\title{
Efficacy of $\mathrm{N}$-acetylcysteine in preventing atrial fibrillation after cardiac surgery: a meta-analysis of published randomized controlled trials
}

Xue-Hui Liu' ${ }^{1,3}$, Chun-Yan Xu and Guang-Hui Fan ${ }^{1 *}$

\begin{abstract}
Background: Atrial fibrillation is a common complication after cardiac surgery. The aim of this study is to evaluate whether N-acetylcysteine (NAC) could prevent postoperative atrial fibrillation (POAF).

Methods: PubMed, Embase and Cochrane Center Register of Controlled Trials were searched from the date of their inception to 1 July 2013 for relevant randomized controlled trials (RCTs), in which NAC was compared with controls for adult patients undergoing cardiac surgery. Outcome measures comprised the incidence of POAF, all-cause mortality, length of intensive care unit (ICU) stay, hospital length of stay, and the incidence of cerebrovascular events. The meta-analysis was performed with the fixed-effect model or random-effect model according to the heterogeneity.

Results: We retrieved ten studies enrolling a total of 1026 patients. Prophylactic NAC reduced the incidence of POAF (OR 0.56; $95 \%$ Cl 0.40 to $0.77 ; P<0.001$ ) and all-cause mortality (OR 0.40; 95\% Cl 0.17 to $0.93 ; P=0.03$ ) compared with controls, but failed to reduce the stay in ICU and overall stay in hospital. No difference in the incidence of cerebrovascular events was observed.

Conclusions: Prophylactic use of NAC could reduce the incidence of POAF and all-cause mortality in adult patients undergoing cardiac surgery. However, larger RCTs evaluating these and other postoperative complication endpoints are needed.
\end{abstract}

Keywords: N-acetylcysteine, Postoperative atrial fibrillation, Cardiac surgery, Meta-analysis

\section{Background}

Atrial fibrillation (AF) is a common complication that occurs after cardiac surgery. The incidence of postoperative atrial fibrillation (POAF) ranges from 10\% to $65 \%$ depending on the type of surgery, perioperative characteristics, methods of monitoring and the definition of $\mathrm{AF}$ $[1,2]$. Previous studies [2-7] indicated that AF is associated with prolonged length of hospital stay, risk of stroke, and mortality, thus extensive research has been conducted to explore the mechanism of POAF and identify the effective method for preventing POAF. Beta-blockers and amiodarone are used widely to minimize the risk of POAF and recommended by current guidelines [8]. However,

\footnotetext{
* Correspondence: fanguanghui59@163.com

'Department of Cardiology, Wuhan General Hospital of Guangzhou Military Command, 627 Wuluo Road, Wuhan, China

Full list of author information is available at the end of the article
}

their use requires caution because of potential drugrelated side effects. Clinical studies have demonstrated higher inflammatory cytokines level and oxidative damage in patients who developed POAF versus those who did not after undergoing cardiac surgery, suggesting that oxidative stress and inflammatory reaction contribute to POAF [9-11].

$\mathrm{N}$-acetylcysteine (NAC) is an antioxidant and antiinflammatory agent, and could reduce cellular oxidative damage and systematic inflammation during cardiac surgery $[12,13]$. Previous meta-analyses showed that the NAC supplementation effectively reduced the incidence of POAF [14,15]. However, of all the included studies, only one [12] treated POAF as primary endpoint and showed a positive result. Recently, a large trial demonstrated that there was no statistical difference in the incidence of POAF between the NAC and placebo groups 


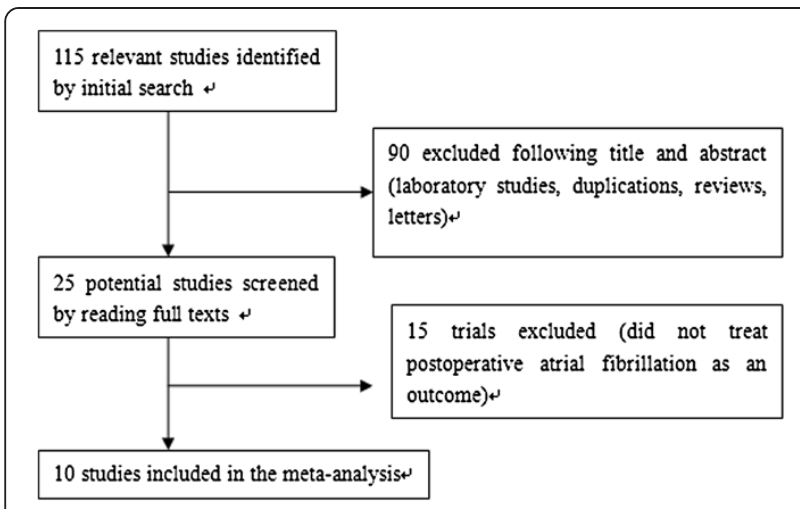

Figure 1 Flow diagram of trials included in the meta-analysis.

[16]. Thus, we conducted an updated meta-analysis to further evaluate the efficacy of NAC on the prevention of POAF in adult patients undergoing cardiac surgery. Besides, we also assessed whether NAC could reduce hospital length of stay, intensive care unit (ICU) stay, all-cause mortality, and cerebrovascular events.

\section{Methods}

Literature search

A comprehensive search was performed to identify all published randomized controlled trials (RCTs) of NAC versus control during cardiac surgery in any language. PubMed, Embase and Cochrane Central Register of Controlled Trials databases were searched from the date of their inception to 1 July 2013. Searched terms included Nacetylcysteine, acetylcysteine, acetadote, mucomyst, heart surgery, cardiac surgery, cardiothoracic surgery, cardiopulmonary bypass, $\mathrm{CPB}$, coronary artery bypass graft, CABG, valve surgery, valvular surgery and atrial fibrillation.

\section{Inclusion and exclusion criteria}

Only RCTs reporting the use of NAC in the prevention of POAF were included in the meta-analysis (including those reporting the concomitant use of other antiarrhythmic agents). Exclusion criteria included: (1) duplicated data; (2) laboratory study; (3) abstract, review or letter to editor; and (4) patient age less than 18 years. Based on these criteria, two investigators (Liu and $\mathrm{Xu}$ )

Table 1 Characteristics of the included studies

\begin{tabular}{|c|c|c|c|c|c|c|}
\hline Reference & $\begin{array}{l}\text { Jadad } \\
\text { score }\end{array}$ & $\begin{array}{l}\text { Surgery } \\
\text { type }\end{array}$ & $\begin{array}{l}\text { Number } \\
\text { NAC/ } \\
\text { control }\end{array}$ & NAC protocol & Medical history & Previous medication \\
\hline $\begin{array}{l}\text { Ozaydin } \\
2008[12]\end{array}$ & 4 & CABG \pm valve & $58 / 57$ & $\begin{array}{l}50 \mathrm{mg} / \mathrm{kg} \text { iv for } 1 \mathrm{~h} \text { before surgery, } \\
\text { then } 50 \mathrm{mg} / \mathrm{kg} / \text { day } 48 \mathrm{~h} \text { after } \\
\text { operation }\end{array}$ & DM, Hypertension, CAD & $\begin{array}{l}\text { BRB, ACEl, Statins, } \\
\text { Acetylsalicylic acid }\end{array}$ \\
\hline $\begin{array}{l}\text { Kazemi } \\
2013[16]\end{array}$ & 5 & CABG \pm valve & $120 / 120$ & $\begin{array}{l}1200 \text { mg orally } 2 \text { times per day from } \\
48 \text { h before and up to } 72 \mathrm{~h} \text { after } \\
\text { heart surgery }\end{array}$ & $\begin{array}{l}\text { DM,CRF,CAD, CHF, } \\
\text { CLD, Hypertension, } \\
\text { Hyperlipidemia }\end{array}$ & $\begin{array}{l}\text { BRB,Statins, ACEl/ARB, } \\
\text { Digoxin, Diuretic }\end{array}$ \\
\hline Eren 2003 [19] & 3 & CABG & $10 / 10$ & $\begin{array}{l}100 \mathrm{mg} / \mathrm{kg} \text { iv for } 1 \mathrm{~h} \text { before and } \\
40 \mathrm{mg} / \mathrm{kg} / \text { day at } 24 \mathrm{~h} \text { after CPB }\end{array}$ & CLD & Not reported \\
\hline Orhan 2006 [20] & 3 & CABG & $10 / 10$ & $\begin{array}{l}50 \mathrm{mg} / \mathrm{kg} \text { iv at the start of induction } \\
\text { of anesthesia for } 30 \text { minutes }\end{array}$ & $\begin{array}{l}\text { DM, CAD, Hypertension, } \\
\text { Hyperlipidemia }\end{array}$ & Not reported \\
\hline Ozaydin 2013 [21] & 5 & $C A B G \pm$ valve & $104 / 104$ & $\begin{array}{l}50 \mathrm{mg} / \mathrm{kg} \text { iv } 1 \mathrm{~h} \text { before and at the } \\
\text { same does for } 48 \mathrm{~h} \text { after surgery }\end{array}$ & $\begin{array}{l}\text { CHF, CLD, DM, CAD } \\
\text { Hypertension }\end{array}$ & BRB, ACEl/ARB, Statins \\
\hline Peker 2008 [22] & 4 & CABG & $19 / 21$ & $\begin{array}{l}50 \mathrm{mg} / \mathrm{kg} \text { iv } 1 \mathrm{~h} \text { before surgery and } \\
50 \mathrm{mg} / \mathrm{kg} / \text { day } 48 \mathrm{~h} \text { after the } \\
\text { operation }\end{array}$ & Not reported & Not reported \\
\hline $\begin{array}{l}\text { Wijeysundera } \\
2007 \text { [23] }\end{array}$ & 5 & CABG \pm valve & $88 / 87$ & $\begin{array}{l}100 \mathrm{mg} / \mathrm{kg} \text { iv over } 30 \mathrm{~min} \text { after } \\
\text { induction of anesthesia, then } 20 \mathrm{mg} \text { / } \\
\mathrm{kg} / \mathrm{h} \text { for } 4 \mathrm{~h} \text { after CPB }\end{array}$ & $\begin{array}{l}\text { CHF, CLD, DM, CVD, } \\
\text { PVD, Hypertension }\end{array}$ & $\begin{array}{l}\text { BRB, CCB, ACEI/ARB, } \\
\text { NSAIDS }\end{array}$ \\
\hline $\begin{array}{l}\text { El-Hamamsy } \\
2007[24]\end{array}$ & 3 & CABG & $50 / 50$ & $\begin{array}{l}600 \mathrm{mg} \text { orally the day before and } \\
\text { the morning of the operation, } \\
150 \mathrm{mg} / \mathrm{kg} \text { iv before skin incision, } \\
\text { then } 12.5 \mathrm{mg} / \mathrm{kg} / \mathrm{h} \text { over } 24 \mathrm{~h}\end{array}$ & $\mathrm{CHF}, \mathrm{CAD}$ & $\mathrm{BRB}, \mathrm{CCB}, \mathrm{ACEl}$ \\
\hline Haase 2007 [25] & 5 & $C A B G \pm$ valve & $30 / 30$ & $\begin{array}{l}150 \mathrm{mg} / \mathrm{kg} \text { iv after anesthesia } \\
\text { induction, then } 50 \mathrm{mg} / \mathrm{kg} \text { iv over } 4 \\
\mathrm{~h} \text {, then } 100 \mathrm{mg} / \mathrm{kg} \text { iv over } 20 \mathrm{~h}\end{array}$ & $\begin{array}{l}\text { DM, CLD, CAD, PVD, } \\
\text { Stroke, Hypertension, } \\
\text { Hyperlipidemia, Carotid } \\
\text { disease }\end{array}$ & Not reported \\
\hline Kim 2011 [26] & 4 & CABG & $24 / 24$ & $\begin{array}{l}100 \mathrm{mg} / \mathrm{kg} \text { iv bolus after anesthetic } \\
\text { induction, then } 40 \mathrm{mg} / \mathrm{kg} / \text { day iv for } \\
24 \mathrm{~h}\end{array}$ & DM, Hypertension & BRB, CCB, ACEl, Diuretics \\
\hline
\end{tabular}


Table 2 Outcomes of included studies in the meta-analysis

\begin{tabular}{|c|c|c|c|c|c|c|c|c|c|c|}
\hline \multirow[t]{2}{*}{ Reference } & \multicolumn{2}{|c|}{ POAF } & \multicolumn{2}{|c|}{ Duration of ICU (hours) } & \multicolumn{2}{|c|}{ Hospitalization (days) } & \multicolumn{2}{|c|}{ Mortality } & \multicolumn{2}{|c|}{ Nonfatal CBV } \\
\hline & NAC & Control & NAC & Control & NAC & Control & NAC & Control & NAC & Control \\
\hline Ozaydin 2008 [12] & $3 / 58$ & $12 / 57$ & NA & NA & $7.7 \pm 3$ & $7.9 \pm 4.2$ & $0 / 58$ & $2 / 57$ & $1 / 58$ & $0 / 57$ \\
\hline Kazemi 2013 [16] & $14 / 120$ & $19 / 120$ & $120 \pm 45.6$ & $115.2 \pm 79.2$ & $7.4 \pm 1.3$ & $7.2 \pm 0.9$ & $1 / 120$ & $2 / 120$ & $1 / 120$ & $1 / 120$ \\
\hline Eren 2003 [19] & $2 / 10$ & $1 / 10$ & NA & NA & NA & NA & $0 / 10$ & $0 / 10$ & $0 / 10$ & $0 / 10$ \\
\hline Orhan 2006 [20] & $0 / 10$ & $1 / 10$ & $23.2 \pm 1.75$ & $22.6 \pm 1.84$ & $7.2 \pm 0.42$ & $7.3 \pm 0.48$ & $0 / 10$ & $0 / 10$ & NA & NA \\
\hline Ozaydin 2013 [21] & $9 / 104$ & $25 / 104$ & NA & NA & NA & NA & $1 / 104$ & $2 / 104$ & $2 / 104$ & 0/104 \\
\hline Peker 2008 [22] & $0 / 19$ & $2 / 21$ & NA & NA & NA & NA & $0 / 19$ & $0 / 21$ & 0/19 & $0 / 21$ \\
\hline Wijeysundera 2007 [23] & $50 / 88$ & $58 / 87$ & 45.6 & $40.8^{*}$ & $8(6-12)$ & $8(6-12)+$ & $0 / 88$ & $7 / 87$ & $4 / 88$ & $4 / 87$ \\
\hline El-Hamamsy 2007 [24] & $4 / 50$ & $6 / 50$ & NA & NA & $5.4 \pm 2.3$ & $5.3 \pm 2.5$ & $3 / 50$ & $0 / 50$ & $0 / 50$ & $0 / 50$ \\
\hline Haase 2007 [25] & $19 / 30$ & $16 / 30$ & 44 & $45^{*}$ & $8(7-11)$ & $8(7-11)+$ & $0 / 30$ & $1 / 30$ & NA & NA \\
\hline Kim 2011 [26] & $4 / 24$ & $8 / 24$ & $72 \pm 36$ & $81.6 \pm 50.4$ & $11.3 \pm 6.3$ & $10.5 \pm 4.5$ & $0 / 24$ & $2 / 24$ & $0 / 24$ & $0 / 24$ \\
\hline
\end{tabular}

Data are number or mean \pm deviation; CBV, cerebrovascular events; NA, data not available; *values expressed as median; + data expressed as median (interquartile range).

independently selected studies for further screening by reading title and/or abstract of all identified literatures. All potential eligible studies were obtained for further assessment.

\section{Data extraction}

Two investigators (Liu and $\mathrm{Xu}$ ) independently extracted the following information from each article: first author's name, year of publication, country of origin, surgery type, perioperative characteristics, NAC protocol, incidence of POAF, length of ICU and hospital stay, all-cause mortality and cerebrovascular events. The primary outcome was the incidence of POAF. The length of hospital and ICU stay, all-cause mortality, and the incidence of cerebrovascular events were considered secondary outcomes. Disagreements were resolved by consensus.

\section{Quality assessment}

The methodological quality of the studies included in the meta-analysis was assessed using validated Jadad 5 point scale [17]. This system emphasizes on the following three parts when defining the quality of a RCT: (1) randomization; (2) blinding; and (3) description of withdrawals and dropouts. A score of one is given for each of the points described. A further point is obtained where the method of randomization and/or blinding is given and is appropriate; where it is inappropriate, a point is deducted. Studies with a score $\leq 2$ were considered low

Table 3 POAF outcome definition and assessment

\begin{tabular}{lll}
\hline Reference & Method of atrial fibrillation assessment & Definition of atrial fibrillation \\
\hline Ozaydin 2008 [12] & $\begin{array}{l}\text { ECGs performed continuously at the first 2 postoperative days } \\
\text { in the ICU, and } 2 \text { times a day routinely when new symptom } \\
\text { developed or observed in the wards. }\end{array}$ & $\begin{array}{l}\text { An irregular narrow complex rhythm with absence } \\
\text { of discrete p-waves lasting longer than } 5 \text { minutes }\end{array}$ \\
Kazemi 2013 [16] & Holter performed continuously for $72 \mathrm{~h}$ after surgery & $\begin{array}{l}\text { More than } 5 \text { minutes of AF or associated with } \\
\text { hemodynamic compromise requiring therapy } \\
\text { immediately. }\end{array}$ \\
Eren 2003 [19] & ECGs were recorded on the first postoperative day & Not reported \\
Orhan 2006 [20] & Not reported & Not reported \\
Ozaydin 2013 [21] & $\begin{array}{l}\text { ECGs performed continuously during ICU stay and all-day Holter } \\
\text { was used during the rest of hospitalization. }\end{array}$ & $\begin{array}{l}\text { The incidence of AF lasting longer than } \\
5 \text { minutes during hospitalization }\end{array}$ \\
Peker 2008 [22] & $\begin{array}{l}\text { ECGs conducted continuously during the first 2 postoperative days } \\
\text { in the ICU, and 2 times per day routinely when new symptom } \\
\text { developed or noted }\end{array}$ & Not reported \\
Wijeysundera 2007 [23] & Continuous telemetry or 12-lead ECGs & Any new atrial fibrillation \\
El-Hamamsy 2007 [24] & Not reported & Not reported \\
Haase 2007 [25] & Not reported & Not reported \\
Kim 2011 [26] & Not reported & Not reported \\
\hline
\end{tabular}

ECG, electrocardiogram. 
quality, and studies with a score $>2$ were considered high quality.

\section{Statistical analysis}

Outcomes were treated as dichotomous (when incidence was reported) or continuous (when the mean and standard deviation were reported) variables. For dichotomous variables, odds ratios (ORs) and 95\% confidence intervals (CIs) were calculated. For continuous variables, the weighted mean difference (WMD) was calculated. Heterogeneity was explored using $\mathrm{I}^{2}$, which describes the percentage of total variation across trials due to heterogeneity rather than chance alone. When $\mathrm{I}^{2}$ was more than $50 \%$, significant statistical heterogeneity was considered to be present [18]. Pooled estimates of efficacy were calculated using the fixed-effects model. If there was heterogeneity, the random-effects model was used. Sensitivity analyses were conducted to test the robustness of overall pooled effect. The presence of publication bias was evaluated by using funnel plot. A two-tailed Pvalue $<0.05$ was considered as significant difference. All statistical analyses were performed using Review Manager version 5.2.

\section{Results}

\section{Identification of eligible studies}

One hundred and fifteen articles were identified by the initial literature search, and 90 studies were excluded after title and abstract screening. Therefore, 25 potential relevant studies were retrieved to read the entire manuscript. Fifteen studies were further excluded because they did not treat POAF as an outcome. Consequently, 10 trials $(\mathrm{n}=1026$ patients $)$ were included in this metaanalysis (Figure 1).

\section{Characteristics of eligible studies}

Patients' characteristics of the included studies are shown in Table 1. The number of patients ranged from $20[19,20]$ to 240 [16]. Of the 10 RCTs, five trials were conducted in Turkey [12,19-22], two in Canada [23,24], one in Iran [16], one in Germany [25], and one in Korea [26]. With the use of Jadad 5 point score, all studies were considered high quality. Both male and female were included in all trials. Only one study [25] included some patients with a history of AF. Diabetic mellitus, hypertension, chronic heart failure, and coronary artery disease were the major concomitant diseases. Five trials [19,20,22,24,26] enrolled 228 patients undergoing CABG only, and the remaining 5 trials $[12,16,21,23,25]$ included 798 patients undergoing valve surgery or combination valve surgery with CABG. NAC administration regimen is also presented in detail in Table 1 , with 8 studies [12,19-23,25,26] using intravenous administration and 2 studies [16,24] using oral administration before cardiac surgery. The duration of NAC administration after cardiac surgery varied from 4 hours [23] to

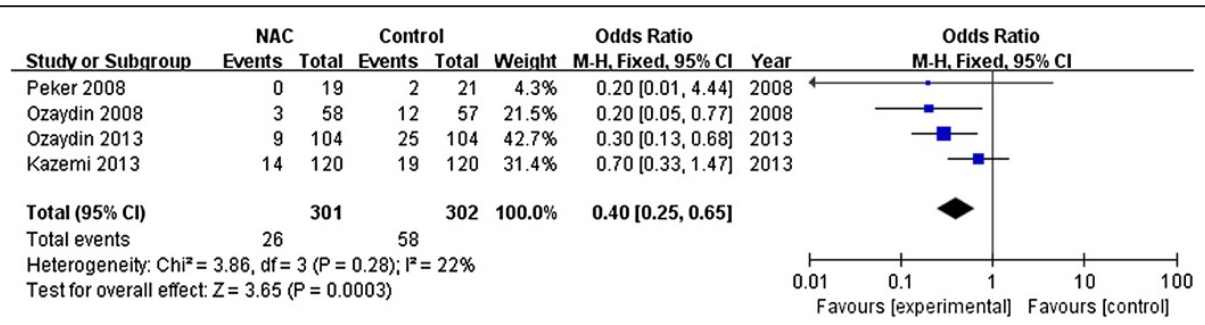

Figure 3 Effects of long-term $\mathrm{N}$-acetylcysteine administration on the prevention of postoperative atrial fibrillation. 


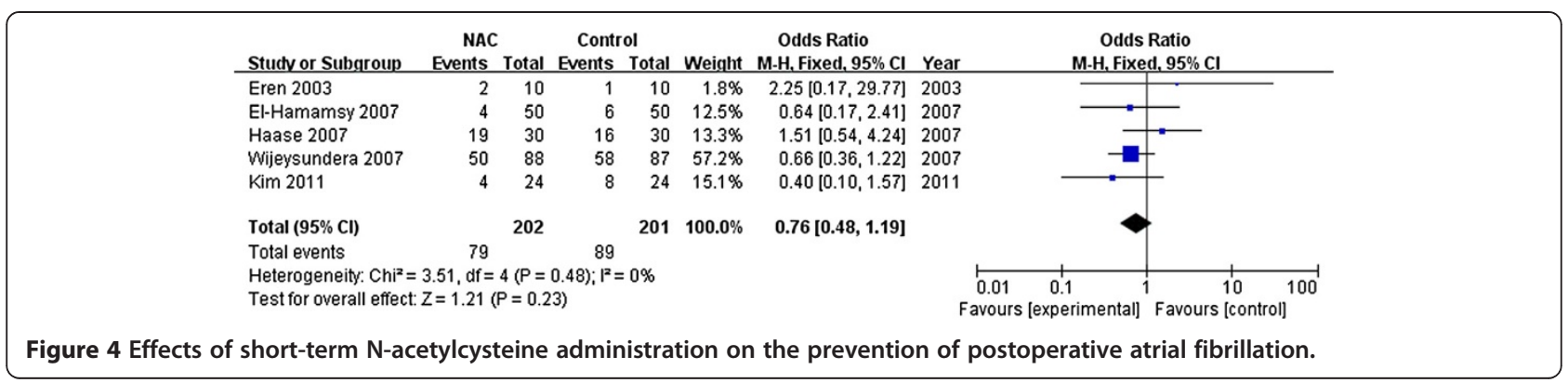

72 hours [16]. Only one study [21] investigated the efficacy of beta-blocker (carvedilol) with NAC on the prevention of POAF.

\section{Incidence of POAF}

The data of the included studies are shown in Table 2. The method of monitoring and the definition of POAF are presented in Table 3 . Of the 10 trials, only four $[12,16,21]$ treated POAF as their primary endpoint.

Pooling all ten RCTs, 20.5\% (105 of 513) of patients given NAC and 28.8\% (148/513) of controls developed POAF. The meta-analysis of ten trials using a fixed-effects model showed that NAC reduced the incidence of POAF (OR 0.56, 95\% CI 0.40 to $0.77 ; P<0.001$; Figure 2) compared with controls, with no heterogeneity between the studies $\left(\mathrm{I}^{2}=15 \%, P=0.31\right)$.

Sensitivity analyses were conducted to test the robustness of the main analysis. We tested whether excluding small sample studies ( $\mathrm{n}<60$ patients) $[19,20,22,26]$ would change the direction of the overall result. The metaanalysis of the remaining studies (OR $0.57,95 \%$ CI 0.40 to $0.80 ; P=0.001)[12,16,21,23-25]$ was similar to the overall result, with little statistical heterogeneity $\left(\mathrm{I}^{2}=42 \%, P=\right.$ 0.12). A trial [25] enrolled some patients with a history of AF, but the pooled results (OR 0.50; 95\% CI 0.35 to 0.71 ; $\left.P<0.001 ; \mathrm{I}^{2}=0 \%, P_{\text {heterogeneity }}=0.56\right)$ did not change when this trial was exclude. In addition, we tested whether different duration of NAC supplementation after cardiac surgery would alter the direction of the overall result. Using the fixed-effects model, the meta-analysis of studies (OR 0.40; 95\% CI 0.25 to $0.65 ; P<0.001 ; \mathrm{I}^{2}=22 \%$, $P_{\text {heterogeneity }}=0.28$; Figure 3$)[12,16,21,22]$ with a longterm (lasting for $48 \mathrm{~h}-72 \mathrm{~h}$ after operation) was similar to the overall effects (OR 0.56 , 95\% CI 0.40 to 0.77 ). However, it failed to reduce the incidence of POAF with a short-term NAC (within $24 \mathrm{~h}$ after surgery) supplementation (OR 0.64; $95 \%$ CI 0.39 to $1.06 ; P=0.09$; $\mathrm{I}^{2}=$ $0 \%, P_{\text {heterogeneity }}=0.7$; Figure 4$)[19,23-26]$.

\section{Length of ICU stay}

Five studies [16,20,23,25,26] reported the data of ICU length of stay, while only three $[16,20,26]$ studies reported the values as mean \pm standard deviation. All the data were converted from days into hours for analysis. Prophylactic NAC was not associated with a reduction in ICU length of stay (WMD 0.60; 95\% CI -0.97 to 2.16; $P=0.45)$. No heterogeneity of included studies was noted $\left(\mathrm{I}^{2}=0 \%, P=0.64\right)$.

\section{Hospital length of stay}

Five $[12,16,20,24,26]$ studies reported values as mean \pm standard deviation, two $[23,25]$ expressed data as median and interquartile range, and one [21] showed values by bar graph. The meta-analysis of the five studies using a fixed-effects model presented that NAC treatment did not reduce the length of hospital stay (WMD 0.09; 95\% CI -0.13 to $0.31 ; P=0.40$; Figure 5 ). No statistical heterogeneity was observed across studies $\left(\mathrm{I}^{2}=0 \%, P=\right.$ $0.76)$.

\section{All-cause mortality}

Death occurred in 5 of 513 patients $(0.9 \%)$ treated with NAC and in 16 of 513 patients (3.1\%) treated with placebo. Use of NAC was associated with a reduction in allcause death (OR $0.40 ; 95 \%$ CI 0.17 to $0.93 ; P=0.03 ; \mathrm{I}^{2}=$ $0 \%, P_{\text {heterogeneity }}=0.44$; Figure 6 ).

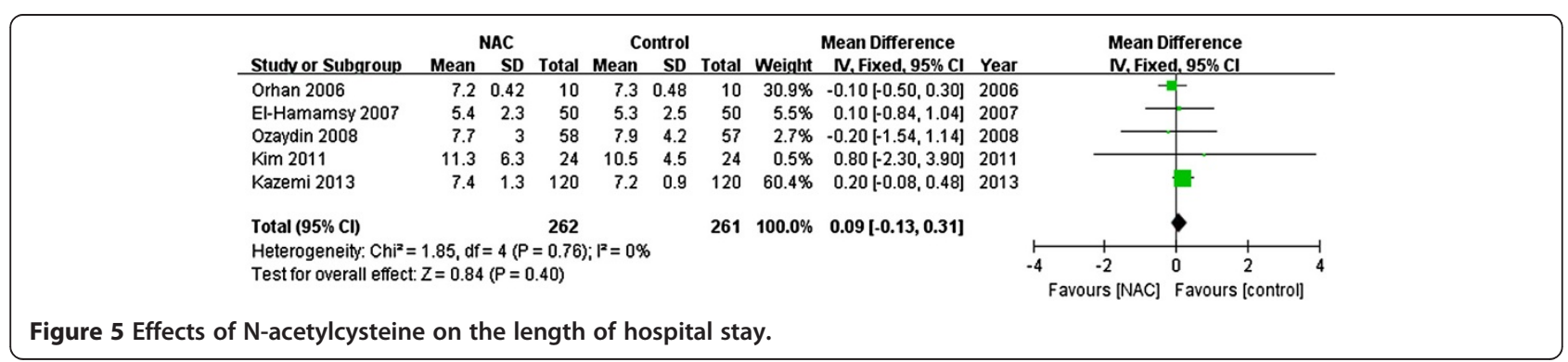




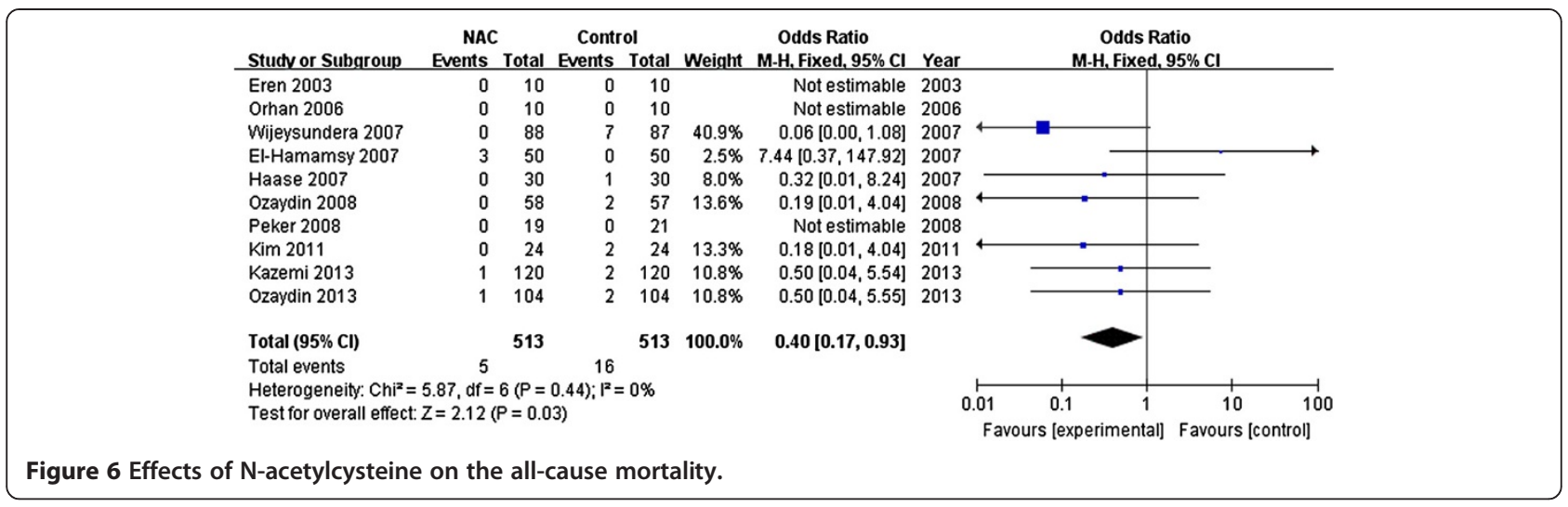

\section{Incidence of cerebrovascular events}

Seven $[12,16,19,21-23,26]$ studies reported the incidence of cerebrovascular events after operation. Cerebrovascular events occurred in 8 of 423 patients $(1.9 \%)$ treated with NAC and in 5 of 424 patients (1.2\%) treated with placebo. Prophylactic use of NAC failed to present a reduction in cerebrovascular accidents (OR 1.68; 95\% CI 0.60 to $\left.4.69 ; P=0.32 ; \mathrm{I}^{2}=0 \%, P_{\text {heterogeneity }}=0.64\right)$.

\section{Publication bias}

The funnel plot for the incidence of POAF was shown in Figure 7. The funnel plot appeared symmetrical, suggesting that there was no potential publication bias among the included trials.

\section{Discussion}

This meta-analysis shows that prophylactic NAC can reduce the incidence of POAF in adult patients undergoing cardiac surgery, with a conclusion similar to the previous meta-analyses $[14,15]$. However, the meta-analysis of trials (OR 0.64; 95\% CI 0.39 to 1.06 ) using a short-term NAC administration, differing from the pooled effect of studies with a long-term (OR 0.51 ; $95 \%$ CI 0.33 to 0.79 ), demonstrates that there is no significant difference compared

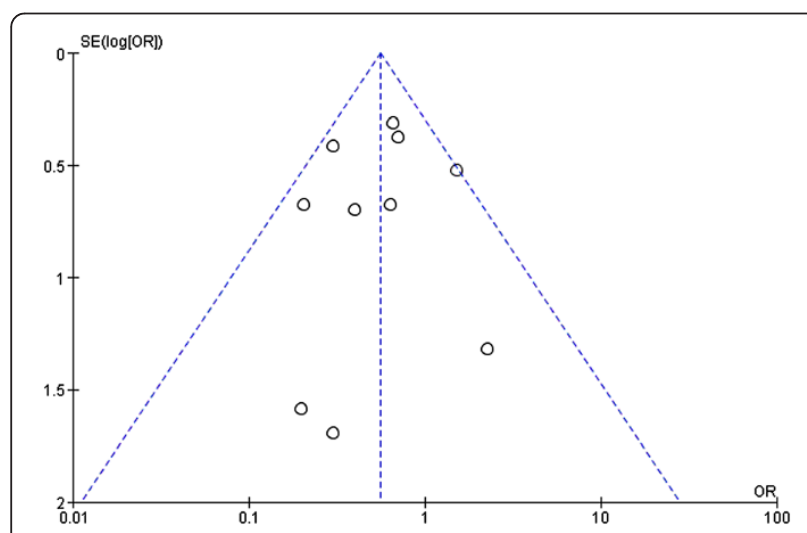

Figure 7 Funnel plot of $\mathrm{N}$-acetylcysteine on the prevention of atrial fibrillation after cardiac surgery. with controls. These findings suggest that NAC can be used for adult patients undergoing cardiac surgery to prevent POAF. It would be more reasonable to prolong the duration of NAC administration up to postoperative day $2-3$. Previous studies presented that on postoperative day 2-3 the inflammatory cytokines levels are the highest, corresponding to the day of the highest incidence of POAF $[7,27]$. To some extent, the different results between short-term and long-term NAC administration may be associated with the anti-inflammatory property of NAC. Additionally, NAC has a generally good safety profile $[16,21,23]$. Of the 10 included studies, only one [23] reported evident side effects among patients, but there was no statistical difference when compared with control group.

An increasing body of evidence demonstrates that oxidative stress and inflammatory reaction play an important role in the pathophysiology of POAF [7,9,28]. Antioxidants, including NAC, have proved to decrease serum levels of molecules markers of cellular oxidative stress in patients undergoing heart surgery [9-11,16,28,29]. NAC is a glutathione precursor, by entering cells and being hydrolyzed to cysteine, it stimulates glutathione synthesis $[12,16]$. In this way, it increases the level of intracellular reduced glutathione, which is often depleted as a response to increased status of inflammation reaction and oxidative stress $[16,30]$. In addition to that, it may also block renin angiotensin system and/or atrial remodeling via its antioxidant actions and anti-inflammatory [12,20,31]. Thus, NAC is a potential agent used for reducing the incidence of POAF in adult patients undergoing cardiac surgery.

Although POAF is often considered both transient and self-limiting $[7,15]$, it can increase the length of ICU and hospital stay, cerebrovascular events, and mortality [3-7]. With regard to ICU and hospital stay, the pooled effects are similar to the pre-existing meta-analyses [13-15], showing no significant difference compared with controls. There is also no significant reduction in the risk of cerebrovascular events (OR 1.68; 95\% CI 0.60 to 4.69) between two groups. This meta-analysis, however, demonstrates 
that prophylactic NAC apparently reduce the occurrence of all-cause mortality (OR $0.40 ; 95 \%$ CI 0.17 to 0.93 ), which differs from the previous meta-analysis (OR 0.81; 95\% CI 0.39 to 1.68 ) conducted by Wang et al. [13].

There are several limitations to this meta-analysis that should be noted. First, there is significant heterogeneity in both the methods of monitoring and the definition of POAF between the studies. AF following cardiac surgery was reported as a clinical outcome in seven studies $[19,20,22-26]$, and only three studies $[12,16,21]$ treated POAF as a primary endpoint. All these may lead to potential overestimation or underestimation of the true incidence of POAF. Second, for the POAF endpoint, the use of beta-blockers and amiodarone was not the standard therapy among most included studies [12,16,19,20,22-26]. Meanwhile, the adjunctive use of NAC in addition to these proven prophylactic strategies is not known. An adjunctive prophylactic protocol, however, that might further prevent POAF without reducing blood prssure and/or heart rate. As such, Ozaydin and his colleagues demonstrated that carvedilol plus NAC significantly reduced the incidence of POAF compared with carvedilol plus placebo [21]. Next, due to different NAC doses and schedules used in these trials, we are unable to evaluate this heterogeneity on clinical outcomes and identify an optimal NAC dose from this meta-analysis. Finally, the positive effect seen is based almost entirely on two trials from the same group $[12,21]$, however, the results of which have not been reproduced in the majority of the other trials.

Future studies should aim to treat the incidence of POAF as a primary endpoint, and standardize the definition of POAF. In addition, these studies should compare various does of NAC, including varying lengths of therapy. It is also important to assess the impact of NAC supplementation on the top of already proven agents for preventing POAF, including beta-blockers, amiodarone, and any other potential prophylaxis.

\section{Conclusions}

This meta-analysis shows that prophylactic use of NAC could reduce the incidence of POAF and all-cause mortality for adult patients undergoing cardiac surgery. However, larger RCTs evaluating these and other postoperative complication endpoints are needed.

\section{Competing interests}

The authors declare that they have no competing interests.

\section{Authors' contributions}

LXH conceived the study, participated in the design, collected the data, performed statistical analyses and drafted the manuscript. XCY helped to collect data. FGH conceived the study, participated the design. All authors read and approved the final manuscript.

\section{Author details}

${ }^{1}$ Department of Cardiology, Wuhan General Hospital of Guangzhou Military Command, 627 Wuluo Road, Wuhan, China. ${ }^{2}$ Department of Endocrinology,
Wuhan General Hospital of Guangzhou Military Command, 627 Wuluo Road, Wuhan, China. ${ }^{3}$ Hubei University of Chinese Medicine, 1 Tanhualin Road, Wuhan, China.

Received: 24 November 2013 Accepted: 10 April 2014

Published: 16 April 2014

\section{References}

1. Omae T, Kanmura Y: Management of postoperative atrial fibrillation. J Anesth 2012, 26:429-437.

2. Maisel WH, Rawn JD, Stevenson WG: Atrial fibrillation after cardiac surgery. Ann Intern Med 2001, 135:1061-1073.

3. Mariscalco G, Engstrom KG: Atrial fibrillation after cardiac surgery: risk factors and their temporal relationship in prophylactic drug strategy decision. Int J Cardiol 2008, 129:354-362.

4. Villareal RP, Hariharan R, Liu BC, Kar B, Lee W, Elayda M, Lopez JA, Rasekh A, Wilson JM, Massumi A: Postoperative atrial fibrillation and mortality after coronary artery bypass surgery. J Am Coll Cardiol 2004, 43:742-748.

5. Likosky DS, Leavitt BJ, Marrin CA, Malenka DJ, Reeves AG, Weintraub RM, Caplan LR, Baribeau YR, Charlesworth DC, Ross CS, Braxton JH, Hernandez F, O'Connor GT: Intra- and postoperative predictors of stroke after coronary artery bypass grafting. Ann Thorac Surg 2003, 76:428-434. discussion 435.

6. Kim MH, Deeb GM, Morady F, Bruckman D, Hallock LR, Smith KA, Karavite DJ, Bolling SF, Pagani FD, Wahr JA, Sonnad SS, Kazanjian PE, Watts C, Williams M, Eagle KA: Effect of postoperative atrial fibrillation on length of stay after cardiac surgery (The Postoperative Atrial Fibrillation in Cardiac Surgery study [PACS(2)]. Am J Cardio/ 2001, 87:881-885.

7. Patel D, Gillinov MA, Natale A: Atrial fibrillation after cardiac surgery: where are we now? Indian Pacing Electrophysiol J 2008, 8:281-291.

8. Fuster V, Ryden LE, Cannom DS, Crijns HJ, Curtis AB, Ellenbogen KA, Halperin JL, Kay GN, Le Huezey JY, Lowe JE, Olsson SB, Prystowsky EN, Tamargo JL, Wann LS, Smith SC, Priori SG, Estes NA, Ezekowitz MD, Jackman WM, January CT, Lowe JE, Page RL, Slotwiner DJ, Stevenson WG, Tracy CM, Jacobs AK, Anderson JL, Albert N, Buller CE, Creager MA, et al: ACCF/AHA/HRS focused updates incorporated into the ACC/AHA/ESC 2006 guidelines for the management of patients with atrial fibrillation: a report of the American College of Cardiology Foundation/American Heart Association Task Force on practice guidelines. Circulation 2011, 2011(123):e269-e367.

9. Elahi MM, Flatman S, Matata BM: Tracing the origins of postoperative atrial fibrillation: the concept of oxidative stress-mediated myocardial injury phenomenon. Eur J Cardiovasc Prev Rehabil 2008, 15:735-741.

10. Ramlawi B, Otu H, Mieno S, Boodhwani M, Sodha NR, Clements RT, Bianchi C, Sellke FW: Oxidative stress and atrial fibrillation after cardiac surgery: a case-control study. Ann Thorac Surg 2007, 84:1166-1172. discussion 1172-1163.

11. Sabol F, Jakubova M, Mitro P, Bomba A, Chmelarova A, Petrasova D, Stancak B, Nagy $V$, Torok $P$, Sebova A: Is there a relationship between inflammatory markers, oxidative stress and postoperative atrial fibrillation? Vnitr Lek 2012, 58:730-734.

12. Ozaydin M, Peker O, Erdogan D, Kapan S, Turker Y, Varol E, Ozguner F, Dogan A, Ibrisim E: N-acetylcysteine for the prevention of postoperative atrial fibrillation: a prospective, randomized, placebo-controlled pilot study. Eur Heart J 2008, 29:625-631.

13. Wang G, Bainbridge D, Martin J, Cheng D: N-acetylcysteine in cardiac surgery: do the benefits outweigh the risks? A meta-analytic reappraisal. $J$ Cardiothorac Vasc Anesth 2011, 25:268-275.

14. Gu WJ, Wu ZJ, Wang PF, Htet Aung LH, Yin RX: N-acetylcysteine supplementation for the prevention of atrial fibrillation after cardiac surgery: a meta-analysis of eight randomized controlled trials. BMC Cardiovasc Disord 2012, 12:10.

15. Baker WL, Anglade MW, Baker EL, White CM, Kluger J, Coleman Cl: Use of $\mathrm{N}$-acetylcysteine to reduce post-cardiothoracic surgery complications: a meta-analysis. Eur J Cardiothorac Surg 2009, 35:521-527.

16. Kazemi B, Akbarzadeh F, Safaei N, Yaghoubi A, Shadvar K, Ghasemi K Prophylactic high-dose Oral-N-Acetylcysteine does not prevent atrial fibrillation after heart surgery: a prospective double blind placebo-controlled randomized clinical trial. Pacing Clin Electrophysiol 2013, 36:1211-1219.

17. Jadad AR, Moore RA, Carroll D, Jenkinson C, Reynolds DJ, Gavaghan DJ, McQuay $\mathrm{HJ}$ : Assessing the quality of reports of randomized clinical trials: is blinding necessary? Control Clin Trials 1996, 17:1-12. 
18. Higgins JP, Thompson SG: Quantifying heterogeneity in a meta-analysis. Stat Med 2002, 21:1539-1558.

19. Eren N, Cakir O, Oruc A, Kaya Z, Erdinc L: Effects of N-acetylcysteine on pulmonary function in patients undergoing coronary artery bypass surgery with cardiopulmonary bypass. Perfusion 2003, 18:345-350.

20. Orhan G, Yapici N, Yuksel M, Sargin M, Senay S, Yalcin AS, Aykac Z, Aka SA Effects of $\mathrm{N}$-acetylcysteine on myocardial ischemia-reperfusion injury in bypass surgery. Heart Vessels 2006, 21:42-47.

21. Ozaydin M, Icli A, Yucel H, Akcay S, Peker O, Erdogan D, Varol E, Dogan A, Okutan H: Metoprolol vs. carvedilol or carvedilol plus $\mathrm{N}$-acetylcysteine on post-operative atrial fibrillation: a randomized, double-blind, placebo-controlled study. Eur Heart J 2013, 34:597-604.

22. Peker O, Peker T, Erdogan D, Ozaydin M, Kapan S, Sutcu R, Ibrisim E: Effects of intravenous $\mathrm{N}$-acetylcysteine on periprocedural myocardial injury after on-pump coronary artery by-pass grafting. J Cardiovasc Surg (Torino) 2008, 49:527-531.

23. Wijeysundera DN, Beattie WS, Rao V, Granton JT, Chan CT: N-acetylcysteine for preventing acute kidney injury in cardiac surgery patients with pre-existing moderate renal insufficiency. Can J Anaesth 2007, 54:872-881.

24. El-Hamamsy I, Stevens LM, Carrier M, Pellerin M, Bouchard D, Demers P, Cartier R, Page P, Perrault LP: Effect of intravenous $\mathrm{N}$-acetylcysteine on outcomes after coronary artery bypass surgery: a randomized, double-blind, placebo-controlled clinical trial. J Thorac Cardiovasc Surg 2007, 133:7-12

25. Haase M, Haase-Fielitz A, Bagshaw SM, Reade MC, Morgera S, Seevenayagam S, Matalanis G, Buxton B, Doolan L, Bellomo R: Phase Il, randomized, controlled trial of high-dose $\mathrm{N}$-acetylcysteine in high-risk cardiac surgery patients. Crit Care Med 2007, 35:1324-1331.

26. Kim JC, Hong SW, Shim JK, Yoo KJ, Chun DH, Kwak YL: Effect of Nacetylcysteine on pulmonary function in patients undergoing off-pump coronary artery bypass surgery. Acta Anaesthesiol Scand 2011, 55:452-459.

27. Cairns JA, Connolly S, McMurtry S, Stephenson M, Talajic M: Canadian Cardiovascular Society atrial fibrillation guidelines 2010: prevention of stroke and systemic thromboembolism in atrial fibrillation and flutter. Can J Cardiol 2011, 27:74-90.

28. Chelazzi C, Villa G, De Gaudio AR: Postoperative atrial fibrillation. ISRN Cardiol 2011, 2011:203179.

29. Liu T, Li G, Korantzopoulos P, Goudevenos JA: Statins and prevention of atrial fibrillation in patients with heart failure. Int J Cardiol 2009, 135:e83-e84.

30. Grinberg L, Fibach E, Amer J, Atlas D: N-acetylcysteine amide, a novel cellpermeating thiol, restores cellular glutathione and protects human red blood cells from oxidative stress. Free Radic Biol Med 2005, 38:136-145.

31. Carnes CA, Chung MK, Nakayama T, Nakayama H, Baliga RS, Piao S, Kanderian A, Pavia S, Hamlin RL, McCarthy PM, Bauer JA, Van Wagoner DR: Ascorbate attenuates atrial pacing-induced peroxynitrite formation and electrical remodeling and decreases the incidence of postoperative atrial fibrillation. Circ Res 2001, 89:E32-E38.

doi:10.1186/1471-2261-14-52

Cite this article as: Liu et al.: Efficacy of $\mathrm{N}$-acetylcysteine in preventing atrial fibrillation after cardiac surgery: a meta-analysis of published randomized controlled trials. BMC Cardiovascular Disorders 2014 14:52

\section{Submit your next manuscript to BioMed Central and take full advantage of:}

- Convenient online submission

- Thorough peer review

- No space constraints or color figure charges

- Immediate publication on acceptance

- Inclusion in PubMed, CAS, Scopus and Google Scholar

- Research which is freely available for redistribution

Submit your manuscript at www.biomedcentral.com/submit
C Biomed Central 